Review Article

(Preliminary Report)

\title{
COVID-19 Follow-Up Centers: An Intervention for Identifying and Managing the Long-Term Effects of COVID-19 Gülcan TECIRLI' ${ }^{1}$ Elife DILLMAÇ ARTUN ${ }^{2}$
}

\begin{abstract}
Various approaches are being developed to manage the short-, medium-and long-term effects of the Novel Corona Virus Disease (COVID-19). However, there is not enough information about how the health of people who have been exposed to the virus will be affected, especially in the long term. Therefore, it has been decided by the Turkish Ministry of Health to establish COVID-19 Follow-up Centers in order to detect possible complications that may develop in patients who have recovered from COVID-19 in the early period and to make necessary interventions in a timely manner. In these centers, it is aimed to reveal the short, medium and long-term side effects of the disease by systematically and regularly monitoring the patients diagnosed with COVID-19, regardless of whether they have any complaints. In this study, the establishment process of the COVID-19 Follow-up Centers, the patient follow-up process has been evaluated. This study is expected to make contribution to the future policies to be implemented in future pandemics.
\end{abstract}

Keywords: COVID-19, complications, long-term effects, follow-up centers.

1. Republic of Turkey Ministry of Health General Directorate of Health Services, R\&D and Health Technology Assessment Department, gulcan.tecirli@saglik.gov.tr, https://orcid.org/ https://orcid.org/0000-0001-62443753

2. Republic of Turkey Ministry of Health General Directorate of Health Services R\&D and Health Technology Assessment Department, elife.dilmac@saglik.gov.tr https://orcid.org/0000-0003-2572-442X

Received : : 15.06 .2021

Accepted : $: 25.06 .2021$

Tecirli, G. and Dilmaç Artun, E. (2021). COVID-19 Follow-Up Centers: An Intervention For Identifying And Managing The Long-Term Effects Of COVID-19, Eurasian Journal Of Health Technology Assessment, 5(1):58. 


\section{Introduction}

Coronaviruses are members of large family of viruses that can cause clinical manifestations ranging from the common cold to severe respiratory failure. The virus that causes COVID19, called SARS-CoV-2, was identified in January 2020. Information regarding the virus and the disease have increased since this period. New information about the short-and longterm effects of the disease are being obtained every day and thus various intervention methods are being developed. However, there is not enough information about how the health of people who have been exposed to the virus will be affected in the long term, since there has not been enough time from the onset of the disease to this day.

The Republic of Turkey Ministry of Health has started a study to establish COVID-19 Follow-up Centers in Turkey and spread them throughout the country in line with the requirements. Through these centers, it is aimed to maintain the standards established in the acute period management of the disease in patient follow-ups, to detect possible complications in a timely manner, to perform timely interventions which is needed, and thereby to minimize the uncertainties that may be experienced by COVID-19 patients in the long term.

As a consequence of this study, which is considered to be a good practice it will be possible to ensure that individuals receive holistic, scientific and long-term treatment or support from a medical-biopsychosocial perspective, and also to create a database for scientific studies on current status and the long-term effects of the disease.

\section{Process and Justifications}

\subsection{Follow-up Centers Establishment Process}

The first COVID-19 case in Turkey was detected on March 11, 2020. Afterwards because of the the rapid increase of patients and the prolongation of the pandemic the establishment of a a follow-up system was planned by the Ministry of Health in order to determine the systemic effects of the virus at an early stage and to make the treatment of the patients without delay. In the planning process the "Health System Strengthening Support Project in scope of the United Nations Development Programme (UNDP) Rapid Response Program to the New Corona Virus Disease (COVID-19)" has been an accelerating factor (UNDP 1, 2020). Thus, the The Follow-Up and Evaluation of the Coronavirus Disease (COVID-19) Patients by the Establishment of Follow-Up Centers Project, which had been prepared by the General Directorate of Health Services, was put into practice with the support of UNDP. In this project ten academicians were assigned from the specialties of Infectious Diseases and Clinical Microbiology, Internal Diseases, Cardiology, Intensive Care, Chest Diseases, Otorhinolaryngology, Neurology, Ophthalmology, Psychiatry and Rheumatology. The current situation analysis was made by these experts and thus the justifications for the establishment of COVID-19 Follow-Up Centers were enhanced (UNDP 2, 2020).

Firstly, the geographical distribution of these centers was evaluated. In this context, initially it was aimed to establish the COVID-19 Follow-up Centers as the pilot center(s) and to resolve problems to be encountered faster. Thus, it was planned to maintain optimum functioning processes and then dissemination of the centers all over the country. In this context, the first pilot center started to serve in Health Sciences University- Ankara Dışkap1 Yıldırım Beyazit Training and Research Hospital on 1 December 2020. The second pilot center started to serve in Eskişehir City Hospital on 13 December 2020. The health information system module to be used in the pilot centers was completed and evaluated. 
Principally a total of 30 COVID-19 Tracking Centers is planned be opened in 30 Health Service Regions in 24 provinces within the scope of the Health Service Regional Structure (Circular, 2010) which has been implemented in Turkey. It was envisaged to establish a center in each city and even to establish a follow-up center in every pandemic hospital if needed in the forthcoming periods.

\subsection{Follow-up Process of Recovered COVID-19 Patients}

A dynamic follow-up algorithm has been developed for the prevention, early diagnosis and timely treatment of diseases, sequelae and complications that may occur in the short, medium and long-term due to the COVID-19 virus in patients who have had COVID-19. The COVID-19 Follow-up Center software was prepared for these algorithms. The software was integrated to the Ministry of Health Public Health Management System (HSYS, 2021).

Periodic follow-up of patients in these centers is planned. In this context, after being diagnosed with COVID-19 and recovered;

$>$ At 0. (first examination after Covid-19), 1. 3. 6. and 12. months for the first year,

$>$ It will be held twice a year for the second year and for the following years if needed.

At the same time, the forms to be used in the follow-up of these patients were arranged and these forms were included in the COVID-19 Follow-up Center software. These forms can be listed as follows;

$>$ Patient information and socio-demographic information form,

$>$ Anamnesis, symptom questioning and physical examination form,

$>$ Laboratory and imaging tests form,

$>$ Scales;

- VAS (Visual Analog Scale, Visual Analog Scale),

- MMRC (Dyspnea Scale, Modified Medical Research Council),

- ECOG (Daily Living Activities Performance Score, Eastern Cooperative Oncology Group),

- Clinical Frailty Score,

- Muscle Strength Assessment (Medical Research Council (MRC) Muscle Strength Scale),

- Psychiatric Evaluation Scale,

- Mini Mental State Test -Educated Patients,

- Mini Mental State Test-Others,

- Quality of Life Scale,

- Malnutrition Universal Screening Test (MUST),

- Mini Nutritional Assessment Test (MNA_SF),

- 6-minute Walk Test (Modified BORG Scale).

Informed Consent Form.

The criterias have been determined for the standarized follow-up process. These are (i) patient evaluations according to their specialties, (ii) which scale to be applied to which patient and (iii) in which cases the patients should be referred to the relevant specialties. In order to operate the follow-up and referral more effectively, information and training materials were prepared for the health professionals who will work in the Follow-up Centers. The training material was made available via the Ministry of Health's Distance Health Education System (USES, 2021). 


\section{Findings}

As of the mid of June 2021, when the study was prepared for publication; the number of patients followed up in two pilot centers is 2228. Among these patients; 1694 of the patients had their first follow-up, 375 of the patients had their second follow-up, 148 of the patients had their third follow-up, 11 of the patients had their fourth follow-up (Table 1).

Table 1. The Number of Patients Followed-Up in Pilot Centers (as of June 15, 2021)

\begin{tabular}{|c|c|c|c|c|}
\hline 1st follow-up & 2nd follow-up & 3rd follow-up & 4th follow-up & Total \\
\hline 1694 & 375 & 148 & 11 & $\mathbf{2 2 2 8}$ \\
\hline
\end{tabular}

\section{Conclusion}

Establishment of Follow-up Centers is considered to be an important initiative to generate systematic data on the long-term effects of COVID-19 in Turkey. On the other hand, it is planned to carry out different studies for the process of expanding the follow-up centers and the evaluation of the findings obtained in the periodic controls.

\section{References}

1. Health System Strenhtenıng Support Project in scope of the United Nations Development Programme (UNDP) Rapid Response Program to the New Corona Virus Disease (COVID-19), (UNDP 1, 2020)

2. Health System Strenhtenıng Support Project in scope of the United Nations Development Programme (UNDP) Rapid Response Program to the New Corona Virus Disease (COVID-19), (UNDP 2, 2020)

3. Health Service Regional Structure (Circular, 2010), Sağlık Bakanlığı (2010). Sağlık Bölge Planlaması, https://www.saglik.gov.tr/TR,11024/saglik-bolge-planlamasi-hakkinda-genelge-ile-hastane-yatak-verolleri-tescil-onayi-201050.html, Access date: 31.05.2021.

4. Republic of Turkey Ministry of Health, General Directorate Of Health Information System, Public Health Management System (HSYS), 2021. https://hsys.saglik.gov.tr/Account/Login?ReturnUrl=http\% 3A\%2F\%2Fhsys.saglik.gov.tr\%3A8080\%2F, Access date: 31.05.2021.

5. Republic of Turkey Ministry of Health, General Directorate of Health Services, Distance Health Education System (USES), 2021. https://uses.saglik.gov.tr/default.aspx, Access date: 31.05.2021. 